\title{
In situ high frequency long term measurements of suspended sediment concentration in turbid estuarine system (Seine Estuary, France): Optical turbidity sensors response to suspended sediment characteristics
}

\author{
Druine Flavie ${ }^{1,{ }^{*}}$, Verney Romaric ${ }^{2}$, Deloffre Julien ${ }^{1}$, Lemoine Jean Philippe ${ }^{3}$, Chapalain Marion ${ }^{2}$, \\ Landemaine Valentin ${ }^{4}$, Lafite Robert ${ }^{1}$
}

${ }^{1}$ Normandie Univ, UNIROUEN, UNICAEN, CNRS, M2C, 76000 Rouen, France

2 IFREMER, DYNECO/DHYSED, ZI pointe du Diable, CS10070 Plouzané, France

${ }^{3}$ GIP Seine Aval, Pole Régional des Savoirs, 115 Boulevard de l'Europe, 76100 Rouen, France

${ }^{4}$ BRGM, 3 Avenue Claude Guillemin, BP 36009, 45060 Orléans, France

* Corresponding author : Flavie Druine, email address : flavie.druine@univ-rouen.fr

\begin{abstract}
:
The aim of this study is to investigate the complex response of optical turbidity sensors (side- and backscattering sensors) to Suspended Particle Matter (SPM) characteristics and the consequences when investigating SPM dynamics from long-term high frequency monitoring networks. Our investigation is based on the analysis of a unique dataset of monthly $12 \mathrm{~h}$ cycle measurements of SPM characteristics such as turbidity, concentration, floc size distribution, floc density and organic matter content in the macrotidal Seine Estuary (France) between February 2015 and June 2016. Results reveal that despite calibration to a Formazin standard, turbidity sensor response to SPM concentrations (in the range of 7$7000 \mathrm{mg} \mathrm{L-1)}$ are strongly variable, from the tidal scale to the annual scale and in different compartments of the Seine Estuary. The variability in the calibration relationships is related to changes in the sensor sensitivity according to (i) the sensor intern technology (mainly due to optical geometry) and (ii) the variability in inherent optical properties (IOP) of SPM.
\end{abstract}

Side-scattering optical instruments (measuring scattering at $90^{\circ}$ ) provide at the annual scale a more stable optical response than backscattering sensor (measuring scattering at angles larger than $100^{\circ}$ ) for a wide variety of floc size and density in the estuarine environment, while at the tidal scale the backscatter sensors are the most accurate. Sensor sensitivity is strongly affected by floc characteristics, i.e. their median size D50, dry density $\rho$ and the scattering efficiency Qb. Results highlight that the median particle diameter contribute to modify the scattering efficiency $\mathrm{Qb}$ as well as the dry density: $\mathrm{Qb}$ increases with increasing floc size, and for a given floc size, $\mathrm{Qb}$ increases with floc density.

In this study, the results are next applied to turbidity data from the long-term automated monitoring network in order to estimate SPM concentrations and estimate the related uncertainties. 


\section{Highlights}

- Optical sensors responses are evaluated from a unique dataset of SPM characteristics. Turbidity/concentration relationships evaluated from the tidal to the annual scale. Flocculation affects the turbidity response of optical sensors. The floc size distribution and floc dry density modify the scattering efficiency. Discussion about long term monitoring network calibration and related uncertainties

Keywords : Turbidity, Suspended sediment concentration, Optical sensor, Flocs, Long term monitoring 


\section{Introduction}

In recent years, assessment of water quality has become a major issue worldwide and is illustrated in Europe by the implementation of the European Water Framework Directive (WFD; 2000/60/EC, Commission of European Community (CEC), 2000) and the Marine Strategy Framework Directive (MSFD; 2008/56/EC, Commission of European Community (CEC), 2008). These guidelines are intended to establish a water policy to protect, conserve and restore the state of groundwater, inland surface waters, estuarine and coastal waters. The WFD/MSFD constitute a strategic lever in water resources management against anthropogenic pressures (Borja, 2006). In this sense, the WFD/MSFD require the monitoring and assessment of biological, hydro-morphological and physicochemical quality parameters. Among all required parameters, turbidity (quantified in Nephelometric Turbidity Units, NTU) can be considered as one of the most relevant marker for monitoring water quality in coastal or estuarine waters. Turbidity can be defined as an index of water clarity, measured by the degree of light scattered by suspended material such as sand, clay, silt, particulate organic 
matter, plankton and other microorganisms in a water volume (ASTM International, 2003; Merten et al., 2014; Rymszewicz et al., 2017). Accordingly, turbidity measurements are used as a proxy to accurately estimate Suspended Particulate Matter concentrations (SPM; in $\mathrm{mg} \mathrm{L}^{-1}$ ). Variations in turbidity help to understand the SPM dynamics and therefore processes which govern particles dynamics and associated contaminants (Deloffre et al., 2005; Chen et al., 2007). It is also a critical parameter limiting light availability and hence controlling phytosynthesis and primary production.

Water sampling and filtration methods are very accurate to monitor SPM concentrations in estuarine systems but time consuming, low frequency and costly. These methods often fail to characterize turbidity variability because of the limitation in term of temporal and spatial coverage (Petus et al., 2010). Consequently, for the WFD/MSFD to be effective, the deployment of high frequency long-term monitoring networks is a suitable tool to assess turbidity and therefore, to estimate SPM concentrations in estuarine systems. For long term high frequency monitoring, turbidity is generally measured by optical sensors (mainly side and back-scattering optical instruments) (Downing et al., 1981; Sternberg et al., 1986; Beach et al., 1992; Kineke et Sternberg, 1992; Schoellhamer, 2002; ACT, 2006).

However, optical turbidity is a complex analytical parameter that is affected by inherent optical properties (IOP) of particles (Boss et al., 2009a, b). Although optical sensors are primarily affected by SPM concentrations (Kineke and Sternberg, 1992), factors such as individual particle size (Ludwig and Hanes, 1990; Conner and De Visser, 1992; Green and Boon, 1993; Merten et al., 2014), particle shape (Bunt et al., 1999; Downing, 2006), sediment color (Sutherland et al., 2000) and degree of flocculation/disaggregation (Gibbs and Wolanski, 1992) also influence sensor response. However, most studies on optical sensors responses to IOP of particles were mainly investigated from controlled calibration experiments in laboratories with homogeneous SPM. In estuaries and coastal seas, suspended particulate matter consists in a population of flocs (or aggregates) with heterogeneous size, density and shape, highly variable in response to complex flocculation 
processes. Laboratory experiments may not reliably represent field conditions because of the difficulty of reproducing the chemical, physical and biological processes involved (Manning and Bass, 2006). Few studies are investigated interactions between IOP's and optical turbidity devices (Boss et al., 2009a, b).

This paper investigates the complex response of optical turbidity sensors (side- or backscatter sensors) to the estuarine SPM variability, from the tidal scale to the annual scale and in different compartments of the Seine Estuary. This issue is examined both in terms of sensor calibration and sensor sensitivity to SPM characteristics. It is supported by a comprehensive dataset of monthly $12 \mathrm{~h}$ cycle measurements of SPM characteristics such as concentration, floc size distribution, floc density, and organic matter content, between February 2015 and June 2016. The results are next applied to turbidity data from the Seine estuary long-term automated monitoring network to estimate SPM concentrations and associated uncertainties.

\section{Study area and field measurements}

\subsection{Regional settings}

The Seine estuary is one of the largest macrotidal estuarine system located in the English Channel, in the northwestern European continental shelf (Figure 1). Hydrological conditions in the Seine Estuary are highly variable and controlled by tidal forcing and seasonally by the river discharge (Guezennec et al.,1999). This estuary is characterized by a maximum tidal range at the mouth of the

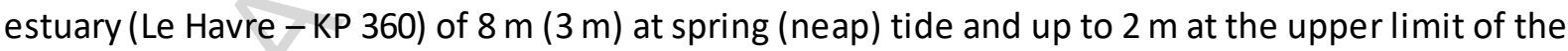
estuary (Poses dam - KP 202). The tidal wave propagates up to $160 \mathrm{~km}$ from the estuary mouth. The mean annual Seine river flow is $450 \mathrm{~m}^{3} \mathrm{~s}^{-1}$ with extreme daily values of up to $2200 \mathrm{~m}^{3} \mathrm{~s}^{-1}$ (Avoine et al., 1981).

The Seine Estuary is divided in three compartments according to spatial and temporal variations of salinity and SPM concentrations, in response to major hydrodynamicforcing (Fairbridge, 
1980; Guezennec et al., 1999). The upper (orfluvial) estuary corresponds to the tide-affected fluvial freshwater zone which is artificially limited upstream by Poses dam (KP 202) and downstream by the salt intrusion limit located near Caudebec en Caux (70 km from the mouth - KP 310). The lower (or marine) estuary is limited to the estuary mouth and corresponds to a low salinity gradient area. Finally, the middle estuary is characterized by strong salinity and SPM concentration gradients and the presence of a distinct estuarine Turbidity Maximum Zone (TMZ). Its maximum mass is estimated to be between 300,000 and 500,000 tones (Avoine et al., 1981) with SPM concentrations between a minimum of $0.05-0.1 \mathrm{~g} \mathrm{~L}^{-1}$ and a maximum of $2-4 \mathrm{~g} \mathrm{~L}^{-1}$ (Lemoine and Verney, 2015).

Sediment transport processes in estuarine environments(i.e. erosion, deposition, flocculation, and advection) control the fate of SPM (Verney et al., 2009). The sediment dynamics in the Seine Estuary is driven by tidal currents coupled with waves at the mouth, the seasonal river discharge and the annual biogeochemical cycle (planktonic bloom development) (Guezennec et al., 1999). In estuaries, SPM primary particles of organic or mineral origin, are mainly aggregated in flocs (or aggregates), of variable shape, size and density, through flocculation/disaggregation processes (Eisma, 1993; Van Leussen, 1994). Turbulence and SPM concentrations are the two major parameters controlling flocculation processes, and to a lesser extent, environmental conditions (salinity and organic matter) modulate the flocculation processes intensity (Dyer, 1989). In the Seine Estuary, the primary particles of few microns (inferior to $10-20 \mu \mathrm{m}$ ) are usually organized in microflocs and macroflocs population, reaching sizes of a few tenth microns during strong ebb/flood current periods, to hundredth of microns during slack periods or by the organic content increase (Verney et al., 2009).

\subsection{Long-term automated monitoring network}

Since 2011, the Seine estuary is instrumented with an automated monitoring network, called SYNAPSES, to follow estuarine water quality (data accessible on website: http://www.seineaval.fr/synapses/). The SYNAPSES network includes 5 stations located from the estuarine fluvial 
compartment to the estuary mouth, including three in the turbidity maximum zone (Figure 1). The stations are equipped with YSI 6600 V2 multi-parameter probe, recording every 5 min the main physico-chemical parameters (conductivity, temperature, turbidity, dissolved oxygen and fluorescence). The data are collected at sub surface $(1 \mathrm{~m})$ and also $1 \mathrm{~m}$ above the bed for the two downstream stations, where vertical gradients are very important (i.e. TMZ - Fatouville and Tancarville). The environmental conditions, biofouling, electrical/mechanical/numerical failures and sensor malfunctions could cause missing or erroneous data, requiring a database cleaning. A first quality check is realized by an automated post-processing routine which includes (i) all numerically invalid data (out of bounds data) and (ii) all periods where optical sensor is emerge (using pressure sensor values). Finally, the post-processing step is verified by data user according to scientific experts.

\subsection{Measurement protocol at the tidal scale}

The field data were collected from 4 SYNAPSES stations during 36 tidal cycles between February 2015 and June 2016. Each campaign was performed during spring tides (tidal range between 6.35 and $7.8 \mathrm{~m}$ ) and for different hydrological conditions (rivers discharges between 168 and $2100 \mathrm{~m}^{3} \mathrm{~s}^{-1}$ ). Data cover both average (14 campaigns around about $450 \mathrm{~m}^{3} \mathrm{~s}^{-1}$ ), low (16 campaigns

around $250 \mathrm{~m}^{3} \mathrm{~s}^{-1}$ ) and high river flow ( 6 campaign greater than $700 \mathrm{~m}^{3} \mathrm{~s}^{-1}$ ) including an exceptional flooding condition (decennial, reaching $2010 \mathrm{~m}^{3} \mathrm{~s}^{-1}$ ). The field survey was carried out in the TMZ (Fatouville Tancarville stations) and further upstream in the estuarine fluvial zone (Rouen - Val des Leux stations).

A profiling frame was deployed with a Sea-Bird 19plus V2 CTD, an OBS3+, an YSI 6600 V2 multiparameter probe (similar to the SYNAPSES stations) and a LISST 100X type C. The three optical turbidity sensors used in this study are described in Table 1 and their operating characteristics detailed in section 3.1. For each tidal cycle, profiles were performed every $15^{\prime}$ for $12 \mathrm{~h}$. Water 
samples were collected every hour, using a horizontal Niskin bottle from the sub-surface $(1 \mathrm{~m})$ and close to the bed $(1 \mathrm{~m})$, thus resulting in about 26 samples per tidal cycle. For a better sensor calibration, water sample are taken close (in time and space) to the sensor measurements. Water samples were used to measure the sample turbidity from an $\mathrm{HACH} 2100 \mathrm{~N}$ IS and for mass concentration estimates. Filtration were performed on pre-weighed glass filters (Whatman GF/F) with a pore size of $0.7 \mu \mathrm{m}$. After filtration, filters were rinsed with distilled water ( $10 \%$ of filtered volume) to remove salt, dried (at $40^{\circ} \mathrm{C}$ for 48 hours), and weighed to obtain the SPM concentration. Eight water samples were also chosen per tidal cycle and were filtered to measure the organic matter fraction by Loss On Ignition (LOI) after burning at $480^{\circ} \mathrm{C}$ for 4 hours.

\section{Material and Methods}

\subsection{Measuring instruments}

\subsubsection{Side-scatter optical probe (YSI)}

The multi-parameter YSI 6600 V2 sensors follows the side-scattering technique of measurements. Light from the emitter (near-infrared at $860 \mathrm{~nm}$ ) enters the sample volume and scatters off particles in the water (Sadar, 2003b). A photodiode detector positioned at 90-degrees relative to this incident light beam detects the light scattered by particles in the sample and converts it ultimately to a turbidity value by using the coefficients provided on the factory calibration certificate (Sadar, 2011). For YSI sensors, values are expressed in nephelometric turbidity units (NTUs) from the measured voltages with an empirically derived equation (ACT, 2007). Multi-point calibration ( 2 or 3-point: 0, 100 and 800 NTU) are used to determine coefficients for the conversion (ACT, 2007; YSI Incorporated, 2012). The side-scattering measurements, the detector position and the light source wavelength used by YSI sensors conform to the International Standards Organization (ISO) Method 7027 (Rasmussen et al., 2009; YSI Incorporated, 2012). 
For in situ measurements, two YSI sensors are used with different turbidity range (YSI-1000 for 0-1000 NTU and YSI-4000 for 0-4000 NTU). Nevertheless, NTU reading from YSI sensors can be different for the same environmental sample (Rasmussen et al., 2009; Sadar, 2003b; YSI Incorporated, 2012). Manufacturers have made improvements and design changes to turbidity sensors over time. A change of sensor model will require an adjustment of the values so that turbidity data collected with one sensor are approximated to an equivalent reading for another sensor by means of conversion factor (YSI Incorporated, 2012). The conversion factor is computed from a data set consisting of concurrent turbidity measurements, collected by these two different sensors. One way of achieving this correction is to operate both sensors in-stream, side-by-side, over a wide range of turbidity conditions (Rasmussen et al., 2009). The site-specific turbidity conversion factor is calculated by means of a median linear regression (method developed in 3.4. Optical sensor calibration method) between the data set of the two sensors. This method is the least likely to be affected by outliers. From this method applied to our field survey, the resulting data set provides two robust conversion factor on the estuarine-specific monitoring sites: NTU_YSI1000=1.44xNTU_YSI4000 for TMZ and NTU_YSI1000=1.76xNTU_YSI4000 for estuarine fluvial area. In this same way, YSI Incorporated (2005) suggests a conversion factor of 1.54 for converting turbidity measurements made with YSI-1000 to comparable measurements made with YSI-4000.

\subsubsection{Backscatter optical sensor (OBS)}

Connected to the Seabird 19plus V2 CTD, the OBS3+ sensor (Downing et al., 1981) is similar to side-scatter optical sensor, but the angle between the incident light source and the detector is less than 90 degrees. A water sample is illuminated by a light source (near-infrared at $850 \mathrm{~nm}$ ) and a photodiode detector detects light scattered (at angles ranging from $140^{\circ}$ and $160^{\circ}$ ) by suspended sediments. A detailed design of the OBS-3+ is given by Downing et al. (1981).

For an optimal measurement, the OBS3+ sensors are dual range sensors having both a lowand high-range output, which increases the overall accuracy and resolution of the measurements 
(Campbell Scientific INC., 2014). In our case, the OBS3+ sensor always outputs both ranges, with a low range at 1000 NTU (for estuarine fluvial area) and a corresponding high range at 4000 NTU (for the TMZ). A wide measurement range allows to deploy the OBS3+ sensor at locations where SPM concentration values larger than $1 \mathrm{~g} \mathrm{~L}^{-1}$ are exceeded frequently. Contrary to YSI sensor, the turbidity reading from the high and low ranges are invariant, requiring no adjustment between both.

\subsubsection{In situ laser sizer}

In addition, a LISST (Laser In Situ Scattering and Transmissometry) 100X type C was simultaneously deployed with the optical sensors, at a $1 \mathrm{~Hz}$ frequency. The LISST sensitivity to the environmental turbulence (optical laser misalignment) required the use of different LISST 100X-C and their factory parameters during the field period. Developed by Sequoia Scientific Inc., it uses laser diffraction technology by means of an infra-red $670 \mathrm{~nm}$ laser diode and ring detectors.

The first step in acquiring data is to record a background scatter file before and after each field measurement. It will verify the system is functioning and that the laser and optics are still in alignment. After recording the background scatter file, the LISST 100X-C allows to estimate the Particles Size Distribution (PSD), the median grain size $\left(D_{50}\right)$ and the sediment volume concentration $(V c)$ of SPM in situ and in real-time. It works by measuring the scattered laser light intensity at different angles with a series of concentric rings detectors. The intensities of light gathered by the rings detectors are inverted to estimate the particle area concentration for 32 log-spaced size categories ranging from 2.5-500 $\mu \mathrm{m}$. These estimates, with an empirical Volume Conversion Constant (VCC) specific to each instrument, then provide a volume concentration distribution $V d\left[\mu \mathrm{L} \mathrm{L}^{-1}\right]$ over this same size range. The total volume concentration $V c\left[\mu \mathrm{LL}^{-1}\right]$ is computed by simple summation of $V d$ over the 32 classes. The LISSTs transmissometer detector is located in the center of the ring detectors in order to measure the light which is not scattered or absorbed (Fugate and Friedrichs, 2002). Extensive instrument descriptions and operating principles can be found in Agrawal and Pottsmith (2000). 
For high SPM concentrations, superior to $0.1 \mathrm{~g} \mathrm{~L}^{-1}$, the beam might be attenuated so much that no light is being transmitted. For this case, the optical Path Reduction Module (PRM) have been used to reduce the total path length in water. Only for TMZ (Tancarville and Fatouville), the PRM are used to reduce the path length of $80 \%$ (down to $1 \mathrm{~cm}$ ). Two steps must be taken into account to compare data with and without PRM: (i) the recording a background scatter file with the PRM in place, required when processing data and (ii) the adjustment of the volume concentration and the beam attenuation in post-processing routine (with $80 \%$ PRM, the volume concentration in columns 1-32 must be multiplied with 5 , and the beam attenuation must be recomputed from the optical transmission [tau] as follow: $-\log (\operatorname{tau}) *(1 / 0.05) /(1-\mathrm{PRM} / 100))$.

\subsection{Sensor metrological quality}

Metrological quality controls of the instruments were achieved prior to each field measurement campaign. The optical sensors tested were installed inside a 3 liters glass beaker coated with black plastic to avoid any interferences from the ambient environment. The sensor was placed near to the center and the solution was homogenized using a magnetic stirrer that rotates at a constant velocity. The control was performed by testing the OBS3+ and YSI sensors response in distilled water $(\approx 0$ NTU) and in a range of Formazin turbidity standards. Calibrated before use with Formazin turbidity standards, the $\mathrm{HACH}$ sensor was used such as turbidity reference. The result of the control calibrations are shown in Figure 2. YSI-1000 and YSI-4000 sensor show a drift compared to $\mathrm{HACH}$ sensor with a metrological error of $10 \%$ and $18 \%$ respectively.

\subsection{Calculation of distribution average dry density}

In order to further characterize the flocculated suspended population in the turbid environment, the distribution average dry density $\rho\left[\mathrm{g} \mathrm{m}^{-3}\right]$ is estimated from knowledge of the total volume concentration $V c$ (e.g. by use of a LISST instrument $-\mu \mathrm{L}^{-1}$ ) and the SPM concentration $C$ (e.g. from the filtered water sample $\left.-\mathrm{g} \mathrm{L}^{-1}\right)$. The dry density can be written with these two parameters: 


\subsection{Optical sensor calibration method}

Using optical sensors in an environment with fine sediments can be problematic due to the strong spatial and temporal variabilities of SPM flocs or aggregates (Sternberg et al., 1991). Therefore, optical sensors must be calibrated from natural suspended sediment in the field site (Sternberg et al., 1986; Downing and Beach, 1989; Kineke and Sternberg, 1992). A linear regression relationship can be found between the SPM concentration $\left[\mathrm{mg} \mathrm{L}^{-1}\right]$ from water samples and the turbidity signal [NTU] for OBS and YSI optical sensors for SSC lower than few $\mathrm{g} \mathrm{L}^{-1}$ (Sternberg et al., 1991; Kineke and Sternberg, 1992). Correlation coefficient obtained from the calibration curve can measure the strength of association between these two variables (Helsel and Hirsch, 2002).

Three methods (Figure 3, a) were tested to estimate the linear relationship between turbidity [NTU] and suspended concentration $\left[\mathrm{mg} \mathrm{L}^{-1}\right]$ :

(i) The linear least-squares regression is performed by estimating many linear relationship between turbidity and SPM concentration. The best approximation is defined as minimizing the Root Mean Square Error (RMSE) between the linear regression and the observed values (Helsel and Hirsch, 2002).

(ii) The Thiel Sen method (affineand linear) is a method for robustly fitting a line to a data set choosing the median slope of all slopes determined by pairs of two-dimensional sample points (Thiel, 1950).

(iii) The last method separates the turbidity/concentration pairs in quantile classes, with the same size ( 5 points perclass quantiles). If the pair number of the last class is less than 5 , they are all integrated into the previous class (Figure $3, \mathrm{~b})$. A linear regression $(C=a N T U$ ) is calculated by randomly choosing one point by class quantiles. This step is repeated by trying all or a fixed number of possible combinations. The distribution of all calculated slopes $a$ (Figure 3, c) gives a median slope 
(50\%) and a 95\% confidence interval (percentiles 2.5 and 97.5 ) to assess the accuracy of the relationship (Landemaine, 2016).

The three methods were tested with data collected on field at the TMZ station (at Fatouville) on June 2015. As far as no outliers are present in the dataset, the three methods provide similar calibration coefficient. The last quantile method has been adopted in this study for two advantages: first, it is the least likely to be affected by outliers contrary to the RMSE method and secondly, it estimates the dispersion range of the NTU/[SPM] relationship thanks to a confidence interval. Though, the method does not minimize the precision error, i.e. the distance between the observed values and the calculated relationship.

\subsection{Uncertainty quantification}

Experimental observation are al ways subject to uncertainties attributed to the field monitoring (sampling method, correlation between sample and instrument measurement, filtration uncertainty, sampling tumbling and homogeneity), the NTU/[SPM] calibration and the human error (Navratil et al., 2011). In our case, the uncertainty on SPM concentration estimates is assessed by calculating an average relative error [\%] that can be expressed as:

Relative error $=\left|\overline{\overline{C_{\text {calculated }}-C_{\text {observed }}}} / \overline{C_{\text {observed }}}\right| \times 100$

With $C_{\text {calculated }}$ is the calculated concentration $\left[\mathrm{mg} \mathrm{L}^{-1}\right]$ which is obtained from the calibration coefficient $a$ [mg L $\left.\mathrm{m}^{-1} \mathrm{NTU}^{-1}\right]$ and the NTU measurements; $C_{\text {observed }}$ correspond to the SPM concentration given by the suspended sediment sample filtration.

\section{Results}

\subsection{Relationship between SPM concentration and turbidity signal}

The regression coefficients (i.e. calibration coefficient) of all calibration curves are given in Table 2 and in Figure 4. The optical sensors, OBS and YSI, have significantly different response, 
revealing two distinct behaviors. For the YSI, two sensors are used with different turbidity range, i.e. YSI-1000 and YSI-4000. The YSI-1000 measurements are adjusted from the conversion factor specific at the monitoring site to compare with the YSI-4000 measurements. The YSI sensors give nearly similar regression coefficient, thus resulting in low variability in optical response. Results show an YSI slope (and mean relative error) range between $1.12( \pm 28 \%)$ and $1.79( \pm 49 \%) \mathrm{mg} \mathrm{L}^{-1} \mathrm{NTU}^{-1}$, for TMZ, with a mean slope of $1.34 \mathrm{mg} \mathrm{L}^{-1} \mathrm{NTU}^{-1}$; and mainly between 1 and $1.5 \mathrm{mg} \mathrm{L}^{-1} \mathrm{NTU} 1$ and extreme punctual values of $0.85( \pm 20 \%)$ and $1.97( \pm 22 \%) \mathrm{mg} \mathrm{L}^{-1} \mathrm{NTU}^{-1}$, for estuarine fluvial area, with a mean slope of $1.26 \mathrm{mg} \mathrm{L}^{-1} \mathrm{NTU}^{-1}$.

On the contrary, the highest values (and mean relative errors) reach close to $3.95( \pm 14 \%)$ and $3.96( \pm 15 \%) \mathrm{mg} \mathrm{L}^{-1} \mathrm{NTU}^{-1}$ and the lowest values are observed around $2.19( \pm 19 \%)$ and $1.75( \pm 16 \%) \mathrm{mg} \mathrm{L}^{-1} \mathrm{NTU}^{-1}$, respectively for TMZ and fluvial estuarine area. Interestingly, although the OBS3+ shows the largest calibration variability, it also provides the most accurate day-by-day estimate of the SSC, with an average relative error of $19 \%$ compared to $24 \%$ for the YSI. Along the annual cycle, the OBS response varies by a factor 2 for similar SPM concentrations. A seasonal variability can be observed for OBS calibration, with the highest values in winter months (e.g. on November to January) and inversely, the lowest values in summer (e.g. on June to August). Many empirical studies (Bunt et al., 1999; Downing, 2006) indicate that the OBS sensor signal can be altered by the variability of the particle optical properties in the environment. In the following sections, we describe and quantify some of these effects on the instrument response.

\subsection{Effect of SPM properties on optical sensor output}

Many parameters can interfere the response of a turbidity sensors. In our context, apart SPM concentrations, the scattering properties of in situ particles, such as the scattering efficiency, the particle size or density may cause the sensor to estimate different turbidity values for similar SPM concentration values. The influence of sensor response to suspended matter properties can be expressed as in the formulation proposed by Sutherland et al. (2000): 
$F=\frac{3}{2}\left[\frac{V E C Q_{b}}{\rho D}\right] \quad \rightarrow \quad \mathrm{T}=\frac{2}{3}\left[\frac{V E C Q_{b}}{\rho D}\right]$

Eq. (3) describes that the radiant flux of light energy $[F-W]$ scattered from a small water sample is proportional to its volume $\left[V-\mathrm{cm}^{3}\right]$, the SPM concentration $\left[C-\mathrm{g} \mathrm{L}^{-1}\right]$, the light incident on the sample $\left[E-\mathrm{W} \mathrm{cm}{ }^{-2}\right]$, the scattering efficiency $\left(Q_{b}\right)$ and inversely proportional to particle diameter $[D-\mu \mathrm{m}]$ and particle density $\left[\rho-\mathrm{g} \mathrm{cm}^{-3}\right]$. The radiant flux of light energy scattered by suspended particles $F[\mathrm{~W}]$ and received by the optical sensor, first converted in volt measurements, is converted in turbidity [T-NTU] values by using the coefficients provided on the factory calibration certificate. From this equation, the following section examines how the change in estuarine particles characteristics and other factor may interfere with optical turbidity measurements.

\subsubsection{Particle size and density}

Suspended sediments in estuaries span a huge size and density range (Mikkelsen and Pejrup, 2001; Verney et al., 2009). Sediment size has the strongest effect on optical sensor signal. Numerous studies have documented this effect in controlled laboratory experiments with individual (unflocculated) sediments such as sand, mud or ground glass (Baker and Lavelle, 1984; Ludwig and Hanes, 1990; Conner and De Visser, 1992; Sutherland et al., 2000; Merten et al., 2014). Although the sediment and methods varied, the data reported by the referenced studies illustrate the general effects of individual sediment grain size on sensor sensitivity. In our case and unlike studies cited above, suspended particulate matters into the Seine Estuary exist as flocculated particles (or flocs) whose properties of size and density, are continuously changing in response to the complex flocculation processes. Figure 5 shows floc size distributions measured by the LISST 100X-C at the deployment locations. The floc size distribution variability differs depending on the estuarine compartments investigated. In the estuarine fluvial zone, the floc size distribution is weakly varying at the tidal scale and along the year. The median particle diameter ranges about 50-120 $\mu \mathrm{m}$, characterized by a mean floc population around $80 \mu \mathrm{m}$. On the contrary, complex resuspension and 
flocculation processes, observed in the TMZ and mainly controlled by tidal dynamics and river flows, cause strong variations in the particle size distribution. Hence, the floc size can range from small microflocs of several tenth of microns to large macroflocs of several hundred of microns.

Referring to the Eq. (3), OBS and YSI results are reported in sensitivity units (turbidity [NTU] per unit of SPM concentration $\left[\mathrm{g} \mathrm{L}^{-1}\right.$ ] - the ratio $T / C$ in the Eq.(3)) that can be used to give a sensor expertise. The sensor sensitivity assess the photo-detector response to a range of different SPM. Thus, the optical sensor sensitivity represents the photo-detector capability to detect a wide variety of particles size (Sadar, 2003a; Merten et al., 2014). The greater the sensitivity, the more sensitive the photo-detector is to particle properties and the more stable the sensor is in term of turbidity and SPM concentrations.

The observed YSI and OBS sensitivities are plotted versus the inverse of the product of dry density $\rho\left[\mathrm{g} \mathrm{m}^{-3}\right]$ and the median particle diameter $\mathrm{D}_{50}[\mathrm{~m}]$ in Figure 6, following Eq. 3 and Sutherland et al. (2000). These results highlight the strong sensitivity of the optical sensor response (OBS and YSI) to SPM IOP. First, Figure 6 shows differences in sensitivities between the two sensors with respect to median floc diameter and dry density. While the YSI sensitivity is between $200 \mathrm{NTU} /\left[\mathrm{g} \mathrm{L}^{-1}\right]$ and $1800 \mathrm{NTU} /\left[\mathrm{g} \mathrm{L}^{-1}\right]$, the OBS sensitivity has a lower sensitivity range, from $100 \mathrm{NTU} /\left[\mathrm{g} \mathrm{L}^{-1}\right]$ and $950 \mathrm{NTU} /\left[\mathrm{g} \mathrm{L}^{-1}\right]$. Therefore, a better YSI sensitivity means a more stable optical response to the variation of the particle optical properties in the estuarine environment.

Secondly, for both sensors (OBS and YSI), similar behaviors are shown according to estuarine compartments. For estuarine fluvial part (Figure 6, red dots), a correlation between the sensor sensitivity and the SPM properties (density and median diameter) can be observed, nearly linear. For TMZ (Figure 6, blue dots) no relationship emerge. These results demonstrate that the product between the median floc diameter and the dry density (Eq. 3) do not fully explain the variability observed on optical sensor responses. 


\subsubsection{The scattering efficiency parameter}

As shown in the previous section, the product of dry density $\rho\left[\mathrm{g} \mathrm{m}^{-3}\right]$ and the median floc diameter $D_{50}[\mathrm{~m}]$ is not sufficient to fully explain the variability in turbidity response. Based on Eq. 3, the last parameter that can affect the sensor optical response is the particle scattering efficiency $Q_{b}$. The scattering efficiency is a dimensionless parameter that represents the particle ability to scatter light. It is the ratio of flux scattered in all directions by suspended particles to the flux geometrically incident to its cross-section (Sutherland et al., 2000).

In case of controlled laboratory experiments with homogeneous SPM, Sutherland et al. (2000) assumed that particle scattering is isotropic. However, in the estuarine environment, this hypothesis may be not valid. SPM form aggregates (micro to macroflocs), whose size, shape, density or nature of constituting particles are strongly variable in space (different estuarine compartments - c.f. Figure 5) and at different time scales (annual/season or tidal cycle). Therefore, according to Downing (2006), the scattering efficiency can be influenced by particle shape (size and density), mineral and organic composition, reflectivity (linked to particle color) and refraction index. In our case, this parameter is unknown, but it can be determined indirectly using Eq. (3):

$V E Q_{b}=\frac{2}{3}\left[\rho D \frac{T}{C}\right] \quad \rightarrow \quad Q_{b} \operatorname{Cst}=\frac{2}{3}\left[\rho D \frac{T}{C}\right]$

From data set, the parameters $T, C, \rho$ and $D$ are known and the parameter $\mathrm{V}$ and $\mathrm{E}$ (sample volume and the sensor light incident respectively) are considered as constant parameter. From these hypotheses and to explain the variability shown above on TMZ, a proxy of the scattering efficiency $Q_{c}$ $\left(Q_{c}=Q_{b} C s t\right)$ are determined from SPM concentrations, OBS or YSI turbidity measurements and plotted versus the median floc diameter $D_{50}[\mathrm{~m}]$ in Figure 7. Relationships can also be established in function of dry density classes ( 6 classes linearly distributed between 0 and $600 \mathrm{~kg} \mathrm{~m}^{-3}$ ). These results enhance that the median floc diameter contributes to modify the scattering efficiency as well as the dry density: $Q_{c}$ increases with increasing floc size, and for a given floc size, $Q_{c}$ increases with floc 
density. Considering classes of densities, slopes for each class showed very low variability per class, i.e. between 0.82 and 1.12 for OBS3+ (with mean value at 0.99 - Figure 7, red dotted line) and between 0.72 and 1.12 for YSI (with mean value at 0.97 ). Then, a constant slope (fixed to 1 for both sensors) was used and the intercept $b$ was recalculated for each class (Figure 7 , black line). The intercept $b$ of each relationship (ranges between 7.47 and 8.06 for OBS and between 7.71 and 8.39 for YSI) is strongly related to the floc dry density (Figure 8).

\section{Discussion}

\subsection{Turbidity sensors and IOPs of natural SPM}

In estuarine systems, the variability in relations between turbidity data and SPM concentrations are linked to changes in sensor sensitivity according to inherent optical properties of flocs. Our results indicate that the YSI sensors are more sensitive than OBS sensor to floc variability, assessing YSI turbidity measurements to be more stable over a wide ranges of floc size, turbidity and SPM concentration (Merten et al., 2014). According to Lewis (1996) and Sadar (2003a), optical response to a given suspension is driven mainly by three critical design components of a sensor: the light source, scattering light detector and optical geometry. In this way, YSI and OBS sensors use the same detector (photodiode) and light source (ISO light requirements: an incident light output to 860 $\mathrm{nm}$ and a spectral bandwidth of less than $60 \mathrm{~nm}$ - Sadar, 2003a); however, the optical geometry differs. This last parameter and especially, the angle of scattered light detection which is the angle formed between the incident light source and the detector, may affect turbidity sensor responses (Downing, 2006). A $90^{\circ}$ detection angle, such as YSI sensor, is the most common detection angle because of its sensitivity to a broad range of size particles (Bin Omar and Bin MatJafri, 2009; Sadar, 2011). On the contrary the OBS3+, uses a detector that is geometrically centered at an angle range between $140^{\circ}$ and $160^{\circ}$ relative to the directional centerline of the incident light beam. This backscatter signal angle is more appropriate when operating in extremely high turbidity samples 
(Sadar, 2011), but our results show that calibration coefficient can be more variable in time depending on SPM IOPs.

In addition to the sensor technology, Sutherland et al. (2000) show that most of the variation in turbidity per unit of SPM concentration (sensor sensitivity) can be due to changes in particle characteristics, i.e. their median size $D_{50}$, dry density $\rho$ and the scattering efficiency $Q_{b}$. When suspensions are mainly constituted of individual grains, i.e. not flocculated, the particle size is the dominant IOP on the optical sensor response, as the particle density and the scattering efficiency will not vary significantly (Baker and Lavelle, 1984; Ludwig and Hanes, 1990; Sutherland et al., 2000; Merten et al., 2014). However, in presence of natural estuarine suspended cohesive sediments, the floc size and density are continuously changing with the ambient environment, i.e., salinity, turbulent intensity and SPM concentration. The difference of floc optical behavior between the two compartments are caused by the effect of flocculation of cohesive sediment on the optical sensor performance. Flocculation occurs widely in estuaries, and is the most intense in the TMZ, as demonstrated by the examination of the floc size distribution variability observed in both compartments (c.f. Figure 5). In the estuarine fluvial zone, the floc size distribution is weakly varying at the tidal scale and along the year, mainly characterized by floc population of $100 \mu \mathrm{m}$, which is in line with the low variability of $Q_{c}$ in this part of the estuary. In the TMZ, the distribution ranges from small microflocs of several tenth of microns to large macroflocs of several hundredth of $\mu \mathrm{m}$, which does explain the strong variability of $Q_{c}$ in this compartment.

The two turbidity sensors used in this study, OBS and YSI, show both drawbacks and advantages. For a single tidal cycle with a given calibration, the OBS3+ (backscatter) sensor is more sensitive to the variation of SPM IOP. In this context, the OBS sensor is more accurate than YSI, providing a particular scientific interest in the study of SPM dynamics. On the contrary, YSI (sidescatter) sensors show the lowest annual variability of the calibration coefficients, and hence seem more suitable for long-term measurements. As a consequence, YSI sensor can be deployed more 
easily on turbidity monitoring network with a unique calibration specific to each site or estuarine compartment.

\subsection{Automated monitoring network calibration}

Monitoring high frequency long-term suspended sediment concentration dynamics in estuaries and coastal seas from optical sensors is a challenging issue, as SPM characteristics are strongly variable and that calibration coefficients are unknown a priori and may require frequent and expensive in situ calibration surveys. In the following section, we investigate and discuss the uncertainty associated to the turbidity-based SPM concentration measurement by testing decreasing spatial and temporal levels of variability, i.e. from the local tidal scale to the global annual scale.

The previous results showed that YSI sensors are weakly influenced by the dynamic changes in floc properties at the annual scale, thus resulting in a good compromise when measuring long term turbidity and SSC. As a reminder, the automated monitoring network (SYNAPSES) in the Seine estuary uses also YSI sensors on each station. Based on these results, a unique median calibration coefficient can be suggested to directly convert turbidity measurements [NTU] from SYNAPSES monitoring network to concentrations [ $\left.\mathrm{mg} \mathrm{L}^{-1}\right]$ by combining all data. Table 3 summarizes the unique calibration coefficient obtained for each specific SYNAPSES stations and for the two estuarine compartments (data aggregated at the annual scale and for all stations within the TMZ and fluvial estuarine compartments).

The unique median calibration coefficients show low variability between SYNAPSES stations, ranging from 1.04 to $1.34 \mathrm{mg} \mathrm{L}^{-1} \mathrm{NTU}^{-1}$. Aggregating stations per compartments, a unique median calibration coefficient (and mean relative error) is calculated for TMZ, with a value of $1.21( \pm 37 \%) \mathrm{mg} \mathrm{L}^{-1} \mathrm{NTU}^{-1}$ and for the estuarine fluvial part, with a value of $1.27( \pm 38 \%) \mathrm{mg} \mathrm{L}^{-1} \mathrm{NTU}^{-1}$. In order to assess the reliability of the unique median calibration coefficient, SYNAPSES uncertainties were estimated in the Figure 9 by confronting the observed concentration with the SPM 
concentrations calculated (i) from the daily calibration coefficient or (ii) from the median calibration coefficient. Except in few cases, uncertainties obtained with the two median calibration coefficient are almost similar, and lower than $50 \%$ of uncertainties. Therefore a unique median calibration coefficient can be used to calibrate YSI turbidity measurements [NTU] to concentrations [mg $\mathrm{L}^{-1}$ ], with an YSI uncertainty of $14-54 \%$ for the TMZ and $18-61 \%$ for the estuarine fluvial part. In few cases, the uncertainty calculated from the unique median calibration coefficient is lower than the uncertainty estimate from the daily calibration coefficient. This is mainly due to the nonminimization of the uncertainty by the quantile calibration method and the presence of potential outliers, not removed when processing the uncertainty.

As station or compartment calibration coefficients present low variability, a single linear relationship NTU/SPM concentration can also be tested for all stations within the Seine Estuary. Figure 10 summarizes all turbidity data and SPM concentrations collected between February 2015 and June 2016 on the following stations: in TMZ, Fatouville (blue) and Tancarville (red); in the estuarine fluvial part, Val des Leux (yellow) and Rouen (green). A single calibration coefficient of 1.21 $\mathrm{mg} \mathrm{L}^{-1} \mathrm{NTU}^{-1}$ is obtained, with a confidence interval between $0.59 \mathrm{mg} \mathrm{L}^{-1} \mathrm{NTU}^{-1}$ and $2.23 \mathrm{mg} \mathrm{L}^{-1} \mathrm{NTU}^{-1}$. A mean relative error is also defined at $37 \%$ which can be considered as an acceptable error for the automated monitoring network calibration (Table 3).

\section{Conclusions}

Side- and back-scattering turbidity sensors (YSI and OBS3+) calibrated against Formazine standards, are tested and their response compared with complex (aggregated) in situ estuarine suspended sediments characteristics. Turbidity-SPM relationships are presented from the tidal scale to the annual scale, in TMZ and fluvial estuarine compartments of the Seine Estuary. The calibration coefficients can vary from 1.75 to $3.96 \mathrm{mg} \mathrm{L}^{-1} \mathrm{NTU}^{-1}$ for OBS3+ sensor and from 1 to $1.5 \mathrm{mg} \mathrm{L}^{-1} \mathrm{NTU}^{-1}$ for YSI sensor. Differences in measured turbidity are linked to the sensor sensitivity, related to (i) the 
sensor intern technology and (ii) the change in inherent optical properties (IOP) of flocs. With a greater sensor sensitivity, the photo-detector positioned at $90^{\circ}$ (YSI) provides a more stable optical response than sensor positioned between 140 and $160^{\circ}(\mathrm{OBS} 3+)$ to the variation of the floc optical properties (i.e. floc size and density) in the estuarine environment.

The variability in sensor sensitivities in respect to SPMcharacteristics (i.e. the median size $D_{50}$, the dry density $\rho$ and the scattering efficiency $\left(Q_{c}\right)$ demonstrate the effect of flocculation of cohesive sediment on the optical sensor performance within the two compartments. In the estuarine fluvial part, the weak floc size distribution variability (floc population around $100 \mu \mathrm{m}$ ) at the tidal and annual scale is related to a low variability of $Q_{c}$. In the TMZ, strong gradients of salinity, turbulent intensity and SPM concentration promote flocculation/disaggregation processes. Hence the floc size ranges from small microflocs of several tenth of microns to large macroflocs of several hundredth of $\mu \mathrm{m}$. This intense floc dynamics is associated to the strong variability of $Q_{c}$ in this compartment. The $Q_{c}$ is shown to be function of the median particle diameter and the dry density: $Q_{c}$ increases with increasing floc size, and for a given floc size, $Q_{c}$ increases with floc density.

Sensor turbidity measurements can be easily calibrated from the sensor-specific linear relationship to reasonably estimate SPM concentrations, but uncertainties can strongly vary according to the sensor and the associated temporal scale. In our case, the OBS3+ (backscatter) sensor will be more accurate than YSI for a single tidal cycle with their respective calibration (uncertainties close to $15-20 \%$ against $20-50 \%$ for YSI sensor). On the contrary, YSI (side-scatter) sensors show a low annual variability of the calibration coefficients and uncertainties, and hence seem more suitable for long-term measurements. These conclusions are applied to turbidity data from a long-term automated monitoring network. With the YSI sensor stability, a unique median calibration coefficient can be suggested for each estuarine compartment ( estuarine fluvial part or $\mathrm{TMZ}$ ) to estimate SPM concentrations $\left[\mathrm{mg} \cdot \mathrm{L}^{-1}\right]$ and associated uncertainties. 


\section{Acknowledgements}

This study was carried out as part of the Seine-Aval French interdisciplinary research program (website: http://www.seine-aval.fr/), supported by the following partners: the French government, the Haute-Normandie Region and the other Regions of the Paris basin, the Agence de l'eau Seine Normandie, and the industrial firms of the Haute-Normandie. The authors would also like to express their gratitude to $\mathrm{M} 2 \mathrm{C}$ and IFREMER teams for their assistance in the fieldwork, and the means of PRESEN platform of FR3130 SCALE.

\section{References}

ACT, Alliance for Coastal Technologies, 2006. Protocols for verifying the performance of in situ turbidity sensor, ACT PV06-01, UMCES/CBL07-48. Available on Web, accessed January 2018, at http://www.act-us.info/Download/Evaluations/Turbidity/Protocols/files/act_pv0601_turbidity_protocols.pdf.

ACT, Alliance for Coastal Technologies, 2007. Performance verification statement for the YSI turbidity sensor, ACT VS05-07, UMCES/CBL07-053. Available on Web, accessed January 2018, at http://www.act-us.info/Download/Evaluations/Turbidity/YSI/files/act_tv07-05_ysi_turbidity.pdf.

Agrawal, Y.C., and Pottsmith, H.C., 2000. Instrument for particle size and settling velocity observations in sediment transport. Marine Geology 168, 89-114.

ASTM International, 2003. D1889-00 Standard test method for turbidity of water. In: ASTM International, Annual Book of ASTM standards, Water and Environmental Technology, V. 11.01, West Conshohocken, Pennsylvania, USA.

Avoine, J., Allen, G.P., Nichols, M., Salomon, J.C. and Larsonneur, C., 1981. Suspended sediment transport in the Seine estuary, France: effect of man-made modifications on estuary-shelf sedimentology. Marine Geology 40, 119-137. 
Baker, E.T. and Lavelle, J.W., 1984. The effect of particle size on the light attenuation coefficient of natural suspensions. Journal of Geophysical Research 89, 8197-8203.

Beach, R.A., Sternberg, R.W. and Johnson, R., 1992. A fiber optic sensor for monitoring suspended sediment. Marine Geology 103, 513-520.

Bin Omar, A. F., and Bin MatJafri, M. Z., 2009. Turbidimeter Design and Analysis: A Review on Optical Fiber Sensors for the Measurement of Water Turbidity. Sensors 9, 8311-8335.

Borja, A., Galparsoro, I., Solaun, O., Muxika, I., Tello, E.M., Uriarte, A., Valencia, V., 2006. The European Water Framework Directive and the DPSIR, a methodological approach to assess the risk of failing to achieve good ecological status. Estuarine, Coastal and Shelf Science 66, 84-96.

Boss, E., Slade, W. and Hill, P., 2009a. Effect of particulate aggregation in aquatic environments on the beam attenuation and its utility as a proxy for particulate mass. Optics Express 17, 94089420.

Boss, E., Taylor, L., Gilbert, S., Gundersen, K., Hawley, N., Janzen, C., Johengen, T., Purcell, H., Robertson, C., Schar D.W.H., Smith, G.J. and Tamburri, N., 2009b. Comparison of inherent optical properties as a surrogate for particulate matter concentration in coastal waters. Limnology and Oceanography Methods 7, 803-810.

Bunt, J.A.C., Larcombe, P. and Jago, C.F., 1999. Quantifying the response of optical backscatter devices and transmissometers to variations in suspended particulate matter. Continental Shelf Research 19, 1199-1220.

Campbell Scientific INC., 2014. OBS-3+ and OBS300 Suspended Solids and Turbidity Monitors Instruction Manual. Available on Web, accessed January 2017, at https://s.campbellsci.com/documents/us/manuals/obs-3+.pdf. 
Chen, Z., Hu, C. and Muller-Karger, F., 2007. Monitoring turbidity in Tampa Bay using MODIS/Aqua 250-m imagery. Remote Sensing of Environment 109, 207-220.

Commission of European Community (CEC), 2000. Directive 2000/60/EC of the European Parliament and of the Council of 23 October 2000 establishing a framework for the community action in the field of water policy. Official Journal of the European Union L237, 1-72.

Commission of European Community (CEC), 2008. Directive 2008/56/EC of the European Parliament and of the Council of 17 June 2008, establishing a framework for community action in the field of marine environmental policy (Marine Strategy Framework Directive). Official Journal of the European Union L164, 19-40.

Conner, C.S. and De Visser, A.M., 1992. A laboratory investigation of particle size effects on an optical backscatterance sensor. Marine Geology 108, 151-159.

Deloffre, J., Lafite, R., Lesueur, S., Lesourd, S., Verney, R., and Guezennec, L., 2005. Sedimentary processes on an intertidal mudflat in the upper macrotidal Seine estuary, France. Estuarine, Coastal and Shelf Science 64, 710-720.

Downing, J., 2006. Twenty-five years with OBS sensors: The good, the bad and the ugly. Continental Shelf Research 26, 229-2318.

Downing, J. and Beach, R.A., 1989. Laboratory apparatus for calibration optical suspended solids sensors. Marine Geology 86, 243-249.

Downing, J., Sternberg, R.W. and Lister, C.R.B., 1981. New instrumentation for investigation of sediment suspension in the shallow marine environment. Marine Geology 42, 19-34.

Dyer, K.R., 1989. Sediment processes in estuaries: future research requirements. Journal of Geophysical Research 94, 14327-14339.

Eisma, D. 1993. Suspended matter in the aquatic environment, Springer-Verlag. 
Fairbridge, R.W., 1980. The estuary: its definition and geodynamic cycle. In: Olausson, E., Cato, I. (Eds.), Chemistry and Bio- geochemistry of Estuaries. Wiley, New-York, pp. 1-35.

Fugate, D.C. and Friedrichs, C.T., 2002. Determining concentration and fall velocity of estuarine particle populations using ADV, OBS, and LISST. Continental Shelf Research 22, 1867-1886.

Gibbs, R.J. and Wolanski, E., 1992. The effects of flocs on optical backscattering measurements of suspended material concentration. Marine Geology 107, 289-291.

Green, M.O. and Boon, J.D., 1993. The measurement of constituent concentrations in nonhomogeneous sediment suspended using optical backscatter sensors. Marine Geology 110, 73-81.

Guezennec, L., Lafite, R., Dupont, J.P., Meyer, R. and Boust, D., 1999. Hydrodynamics of suspended particulate matter in the tidal freshwater zone of a macrotidal estuary (the Seine estuary, France). Estuaries 22, 717-727.

Helsel, D.R., and Hirsch, R.M., 2002. Statistical methods in water resources-hydrologic analysis and interpretation: U.S. Geological Survey Techniques of Water-Resources Investigations, book 4, chap. A3, 510p., available on Web, accessed January 2017, at http://www.cala.ca/sampling/40_Statistical_Methods_in_Water_Resources.pdf.

Kineke, G.C., Sternberg, R.W., 1992. Measurements of high concentration suspended sediments using the optical back- scatterance sensor. Marine Geology 108, 253-258.

Landemaine, V., 2016. Erosion des sols et transferts sédimentaires sur les bassins versants de l' Ouest du Bassin de Paris: analyse, quantification et modélisation à l'échelle plurianuelle (French version). PhD Thesis, University of Rouen, France, 234p.

Lemoine, J.P., and Verney, R., 2015. Fonctionnement hydro-sédimentaire de l'estuaire de la Seine. Fascicule Seine-Aval 3.3, 64p. 
Lewis, J., 1996. Turbidity-controlled Suspended Sediment Sampling for Runoff-event Load Estimation. Water Resources Research 32, 2299-2310.

Ludwig, K.A., Hanes, D., 1990. A laboratory evaluation of optical backscatterance susp ended solids sensors exposed to sand-mud mixtures. Marine Geology 94, 173-179.

Manning, A.J. and Bass, S.J., 2006. Variability in cohesive sediment settling fluxes: Observations under different estuarine tidal conditions. Marine Geology 235, 177-192.

Merten, G.H., Capel, P.D. and Minella, J.P.G., 2014. Effects of suspended sediment concentration and grain size on three optical turbidity sensors. Journal Soils Sediment 14, 1235-1241.

Mikkelsen, O.A. and Pejrup, M., 2001. The use of a LISST-100 laser particle sizer for in-situ estimates of floc size, density and settling velocity. Geo-Marine Letters 20, 187-195.

Navratil, O., Esteves, M., Legout, C., Gratiot, N., Nemery, J., Willmore, S. and Grangeon, T., 2011. Global uncertainty analysis of suspended sediment monitoring using turbidimeter in a small mountainous river catchment. Journal of Hydrology 398, 246-259.

Petus, C., Chust, G., Gohin, F., Doxaran, D., Froidefond, J., Sagarminaga, Y., 2010. Estimating turbidity and total suspended matter in the Adour River plume (South Bay of Biscay) using MODIS 250-m imagery. Continental Shelf Research 30, 379-392.

Rasmussen, P.P., Gray, J.R., Glysson, G.D., Ziegler, A.C., 2009. Guidelines and procedures for computing times-series suspended-sediment concentration and loads from in-stream turbiditysensor and streamflow data. U.S. Geological Survey Techniques and Methods Book 3, Chapter 4, $53 p$.

Rymszewicz, A., O’Sullivan, J.J., Bruen, M., Turner, J.N., Lawler, D.M., Conroy, E., Kelly-quinn, M., 2017. Measurement differences between turbidity instruments, and their implications for 
suspended sediment concentration and load calculations: A sensor inter-comparison study. Journal of Environmental Management 199, 99-108.

Sadar, M.J., 2003a. Turbidity Science. Technical Information Series-Booklet No. $11,1^{\mathrm{er}}$ Edition. Hach Company, Loveland, Colorado, 26p.

Sadar, M., 2003b. Turbidimeter Instrument Comparison: Low-Level Sample Measurements. Technical Information Series, $1^{\mathrm{er}}$ Edition. Hach Company, Loveland, Colorado, 56p.

Sadar, M., 2011. Technologies for Measuring Turbidity in Drinking Water Production. WaterWorld, Automation-Technology, $1^{\mathrm{er}}$ edition. Hach Company, Loveland, Colorado, $4 \mathrm{p}$.

Schoellhamer, D.H., 2002. Variability of suspended-sediment concentration at tidal to annual time scales in San Francisco Bay, USA. Continental Shelf Research 22, 857-1866.

Sternberg, R.W., Johnson, R.V. II, Cacchione, D.A. and Drake, D.E., 1986. An instrument system for monitoring and sampling suspended sediment in the benthic boundary layer. Marine Geology 71, 187-199.

Sternberg, R.W., Kineke, G.C., Johnson, R.V., 1991. An instrument system for profiling suspended sediment, fluid, and flow conditions in shallow marine environments. Continental Shelf Research 11, 109-122.

Sutherland, T.F., Lane, P.M., Amos, C.L., Downing, J., 2000. The calibration of optical backscatter sensors for suspended sediment of varying darkness level. Marine Geology 162, 587-597.

Theil, H., 1950. A rank-invariant method of linear and polynomial regression analysis. I, II, III. Nederlandse Akademie Van Wetenschappen Proceedings 53,386-392, 521-525 and 1397-1412.

Van Leussen, W. 1994. Estuarine macroflocs: their role in fine grained sediment transport. Utrecht, University of Utrecht, 488p. 
Verney, R., Lafite, R., and Brun-Cottan, J.-C., 2009. Flocculation potential of estuarine particles: The importance of environmental factors and of the spatial and seasonal variability of suspended particulate matter. Estuaries Coasts 32, 678-693.

YSI Incorporated, 2005. Reconciling 6026 and 6136 turbidity data. Available on Web, accessed January 2017, at https://www.ysi.com/File\%20Library/Documents/Technical\%20Notes/T615Reconciling-6026-and-6136-Turbidity-Data.pdf.

YSI Incorporated, 2012. User Manual: 6-Series, Multiparameter Water Quality Sondes. Available on Web, accessed January 2017, at https://www.ysi.com/File\%20Library/Documents/Manuals/069300-YSI-6-Series-Manual-RevJ.pdf. 


\section{CAPTIONS}

\section{Table Captions}

Table 1 : Summary of factor sensors specifications.

Table 2 : Range of observed turbidity values $\left[\mathrm{mg} \mathrm{L}^{-1}\right.$ ] and regression analyses results for OBS and YSI turbidity sensor with their associated uncertainties. Missing values are represented by the symbol NA (Not Available).

Table 3: Summary of SYNAPSES calibration coefficients and mean relative error by station, by estuary compartment (fluvial and TMZ part) and inter-site. 


\section{Figure Captions}

Figure 1: The Seine Estuary and location of the 5 SYNAPSES stations. KP is the along river kilometric point distance from Paris.

Figure 2: Metrological quality control of the OBS 3+ and YSI 6600 V2 (0-1000 and 0-4000 NTU) sensors versus $\mathrm{HACH}$ turbidity referenced. Dashed black line represent the 1:1 line.

Figure 3: (a) Division of the turbidity/SPM concentration pairs in quantileclasses - (b) Distribution of calculated slope with all possible combinations and (c) Calibration relationship between turbidity signal [NTU] and suspended particle matter concentration [mg L ${ }^{-1}$ ] using 3 methods at TMZ on June, 2015.

Figure 4: Calibration curve slope results of (a-b) OBS and (c-d) YSI turbidity sensor for each tidal cycle campaigns, in the fluvial and TMZ compartments. The calibration coefficient and the confidence interval are plotted for each campaign.

Figure 5: Cumulative frequency curves of 218 samples distributed on estuarine fluvial part (red line) or TMZ (blue line), between February 2015 and June 2016. The bold curves correspond to the mean of cumulative frequency by estuarine compartment.

Figure 6: Relation between the inverse of product of median size $D_{50}$ and dry density $p\left[\mathrm{~m}^{2} \mathrm{~g}^{-1}\right]$ and the sensor sensitivity (NTU/[g L $\left.{ }^{-1}\right]$ ) of (a) the OBS and (b) YSI turbidity sensor.

Figure 7: Linear relation between the scattering efficiency $\boldsymbol{Q} \boldsymbol{b}$ and the median particle diameter $\boldsymbol{D}_{\mathbf{5 0}}[\mathrm{m}]$ measured on TMZ compartment from OBS3+ sensor, with the variable slope (red dotted line) and the constant slope (black line). Each graphic represent different dry density classes (color bar).

Figure 8: Variation of coefficient $b$ as a function of the dry density classes, for OBS3+ and YSI sensors.

Figure 9: SYNAPSES uncertainties [\%] calculated from the daily calibration (point symbol) and a global median calibration (square symbol), for (a) the TMZ and (b) the estuarine fluvial part.

Figure 10: Calibration relationship between turbidity signal (NTU) from all SYNAPSES stations and SPM concentration [mg L ${ }^{-1}$ ] from water samples. The calibration coefficient and the confidence interval are also plotted. 


\section{Table 1}

\begin{tabular}{llll}
\hline Sensors & HACH 2100N IS & YSI 6600 V2 & OBS3+ (CTD) \\
\hline $\begin{array}{l}\text { Optical method } \\
\text { Light source }\end{array}$ & Optical side-scattering & Optical side-scattering & Optical backscattering \\
Wavelength & IR-LED & IR-LED & IRED \\
Photodiode detector & $860 \pm 30 \mathrm{~nm}$ & $860 \pm 30 \mathrm{~nm}$ & $850 \pm 5 \mathrm{~nm}$ \\
& $90^{\circ}$ & $90^{\circ}$ & $140-160^{\circ}$ \\
Range & $0.01-1000 \mathrm{NTU}$ & $0-1000 \mathrm{NTU}$ or & $0-1000 \mathrm{NTU}$ and \\
& & $0-4000 \mathrm{NTU}$ & $0-4000 \mathrm{NTU}$ \\
Accuracy & $\pm 2 \%$ & $\pm 2 \%$ & Mud: $\pm 2 \%$ \\
& & & Sand: $\pm 4 \%$ \\
Resolution & $0.001 \mathrm{NTU}$ & $0.1 \mathrm{NTU}$ & $0.001 \mathrm{NTU}$ \\
Sampling frequency & - & $1 \mathrm{~Hz}$ & $2 \mathrm{~Hz}$ \\
\hline
\end{tabular}


Table 2

\begin{tabular}{|c|c|c|c|c|c|}
\hline $\begin{array}{l}\text { TIME_Station } \\
\text { [yymmdd_station] }\end{array}$ & $\begin{array}{l}\text { RANGE } \\
{\left[\mathrm{mg} \mathrm{L}^{-1}\right]}\end{array}$ & $\begin{array}{c}\text { OBS3+ Median Slope } \\
{\left[\mathrm{mg} \mathrm{L}^{-1} \mathrm{NTU}^{-1}\right]}\end{array}$ & $\begin{array}{c}\text { OBS3+ Relative } \\
\text { Error [\%] }\end{array}$ & $\begin{array}{l}\text { YSI Median Slope } \\
{\left[\mathrm{mg} \mathrm{L}^{-1} \mathrm{NTU}^{-1}\right]}\end{array}$ & $\begin{array}{l}\text { YSI Relative } \\
\text { Error [\%] }\end{array}$ \\
\hline 150218_TMZ & $74-6650$ & 3.95 & 14.2 & 1.79 & 49.2 \\
\hline 150219_FLUVIAL & $7-35$ & 3.14 & 13.9 & 1.22 & 12.5 \\
\hline 150319_TMZ & $109-3856$ & 3.14 & 14.9 & 1.27 & 22.5 \\
\hline 150321_TMZ & $114-4720$ & 3.06 & 14.3 & 1.44 & 26.3 \\
\hline 150323_FLUVIAL & $11-47$ & 2.51 & 15.0 & 1.31 & 27.3 \\
\hline 150324_FLUVIAL & $8-24$ & 2.21 & 7.9 & 1.24 & 12.1 \\
\hline 150420_FLUVIAL & $8-41$ & 2.06 & 16.4 & 1.18 & 30.5 \\
\hline 150422_MZ & $77-5691$ & 2.75 & 10.0 & 1.13 & 28.1 \\
\hline 150516_TMZ & $55-501$ & 2.67 & 14.0 & 1.25 & 26.2 \\
\hline 150518_TMZ & $53-4752$ & 3.09 & 21.2 & 1.48 & 25.1 \\
\hline 150519_FLUVIAL & $8-46$ & 2.56 & 14.3 & 1.27 & 27.5 \\
\hline 150520_FLUVIAL & $10-39$ & 2.26 & 10.8 & 0.98 & 31.3 \\
\hline 150617_TMZ & $47-2554$ & 2.63 & 20.3 & NA & NA \\
\hline 150618_FLUVIAL & $10-63$ & 1.75 & 15.6 & NA & NA \\
\hline 150703_TMZ & $50-2926$ & 2.19 & 19.7 & NA & NA \\
\hline 150704_FLUVIAL & $11-23$ & 1.88 & 12.8 & 1.26 & 31.4 \\
\hline 150706_TMZ & $63-3897$ & 2.28 & 29.8 & 1.12 & 28.2 \\
\hline 150707_FLUVIAL & $26-118$ & 2.19 & 15.2 & 1.13 & 37.0 \\
\hline 150829_FLUVIAL & $7-20$ & 1.81 & 16.3 & 1.34 & 16.6 \\
\hline 150831_FLUVIAL & $17-170$ & 2.41 & 22.7 & 1.26 & 20.6 \\
\hline 150901_TMZ & $60-4067$ & NA & NA & 1.33 & 18.3 \\
\hline 150903_TMZ & $73-4897$ & 2.76 & 23.2 & 1.25 & 11.8 \\
\hline 150927_FLUVIAL & $21-128$ & 2.60 & 41.7 & 1.31 & 15.8 \\
\hline 150929_TMZ & $60-4647$ & 2.74 & 15.0 & 1.35 & 23.3 \\
\hline 151027_TMZ & $78-7231$ & 2.63 & 19.6 & 1.26 & 20.8 \\
\hline 151028_FLUVIAL & $22-191$ & 3.06 & 27.7 & 1.44 & 24.2 \\
\hline 151029_TMZ & $183-6227$ & 2.69 & 28.7 & 1.26 & 11.6 \\
\hline 151030_FLUVIAL & $11-45$ & 3.11 & 13.4 & 1.61 & 14.7 \\
\hline 151124_TMZ & $138-6941$ & 3.03 & 19.0 & 1.31 & 35.4 \\
\hline 151126_FLUVIAL & $20-98$ & 3.96 & 15.1 & 1.97 & 22.4 \\
\hline 160223_FLUVIAL & $21-96$ & 2.43 & 17.5 & 0.85 & 20.7 \\
\hline 160225_TMZ & $68-6493$ & 3.69 & 21.5 & 1.39 & 25.8 \\
\hline 160308_FLUVIAL & $14-141$ & 3.73 & 30.9 & 1.16 & 31.9 \\
\hline 160312_TMZ & $93-690$ & 3.09 & 24.1 & 1.31 & 23.3 \\
\hline 160605_FLUVIAL & $23-135$ & 1.96 & 19.2 & 0.93 & 17.7 \\
\hline 160607_TMZ & $41-1844$ & 2.83 & 29.7 & 1.42 & 28.1 \\
\hline
\end{tabular}


Table 3

\begin{tabular}{|c|c|c|c|c|c|}
\hline \multirow{2}{*}{ SYNAPSES Station } & \multirow{2}{*}{$\begin{array}{l}\text { Calibration } \\
\text { Coefficient } \\
{\left[\mathrm{mg} \mathrm{L}^{-1} \mathrm{NTU}^{-1}\right]}\end{array}$} & \multicolumn{2}{|c|}{ Confidence Interval } & \multirow{2}{*}{$\begin{array}{c}\text { Mean } \\
\text { relative error } \\
{[\%]}\end{array}$} & \multirow{2}{*}{$\begin{array}{l}\text { MES/NTU } \\
\text { pair number }\end{array}$} \\
\hline & & $\begin{array}{l}\text { Inferior } \\
\text { limit }\end{array}$ & $\begin{array}{l}\text { Superior } \\
\text { limit }\end{array}$ & & \\
\hline FATOUVILLE & 1.18 & 0.63 & 1.84 & 31 & 452 \\
\hline TANCARVILLE & 1.34 & 1.07 & 2.25 & 47 & 113 \\
\hline VAL DES LEUX & 1.31 & 0.91 & 1.82 & 25 & 178 \\
\hline ROUEN & 1.04 & 0.72 & 1.39 & 28 & 77 \\
\hline TMZ & 1.21 & 0.63 & 1.93 & 37 & 565 \\
\hline FLUVIAL & 1.27 & 0.86 & 1.82 & 38 & 255 \\
\hline ALL SITES & 1.21 & 0.59 & 2.23 & 37 & 820 \\
\hline
\end{tabular}


Highlight ( 3 to 5 bullet points /maximum 85 characters, including spaces, per bullet point)

Highlight 1: Optical sensors responses are evaluated from a unique dataset of SPM characteristics

Highlight 2: Turbidity/concentration relationships evaluated from the tidal to the annual scale

Highlight 3: Flocculation affects the turbidity response of optical sensors

Highlight 4: The floc size distribution and floc dry density modify the scattering efficiency

Highlight 5: Discussion about long term monitoring network calibration and related uncertainties 


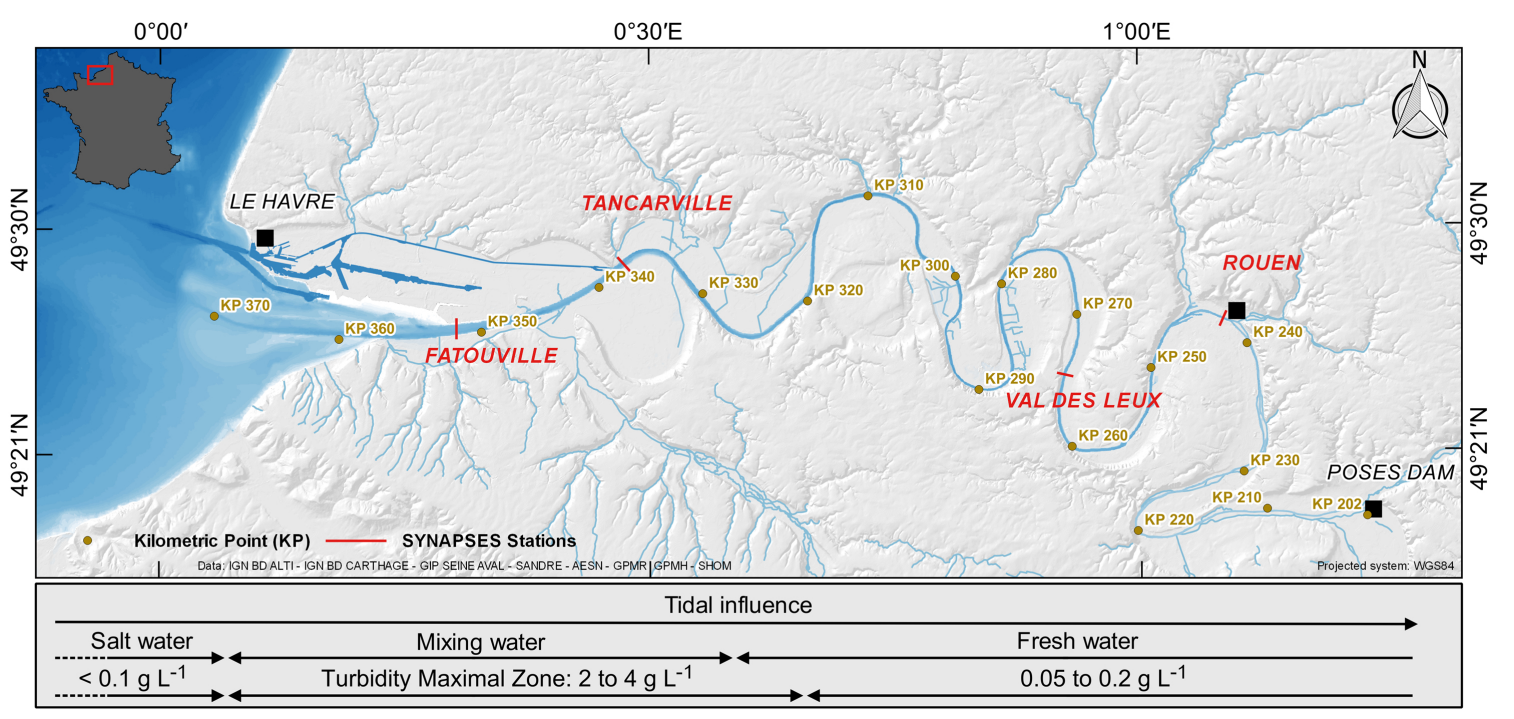

Figure 1 


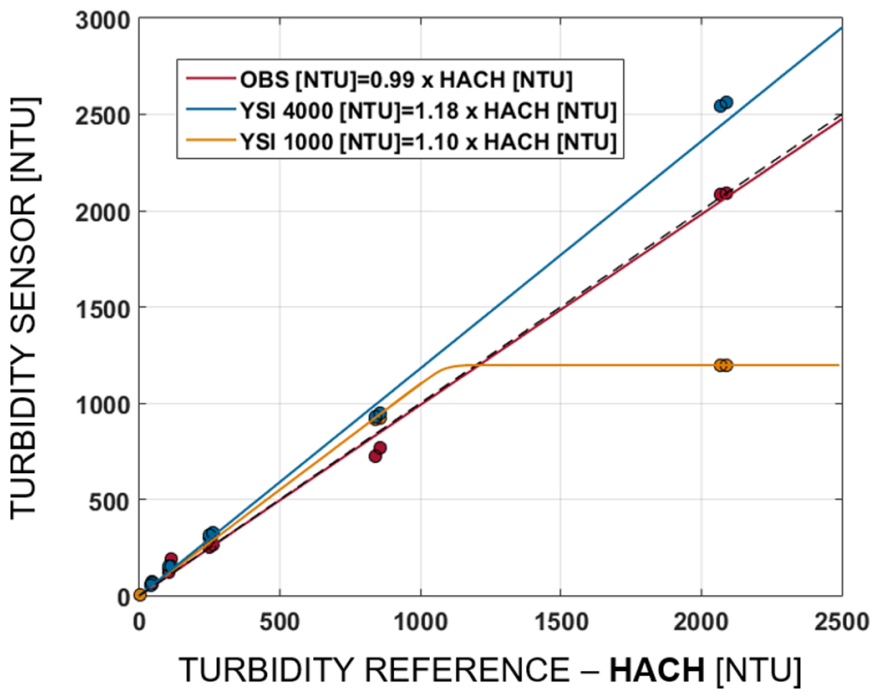

Figure 2 
TMZ - 17 June 2015
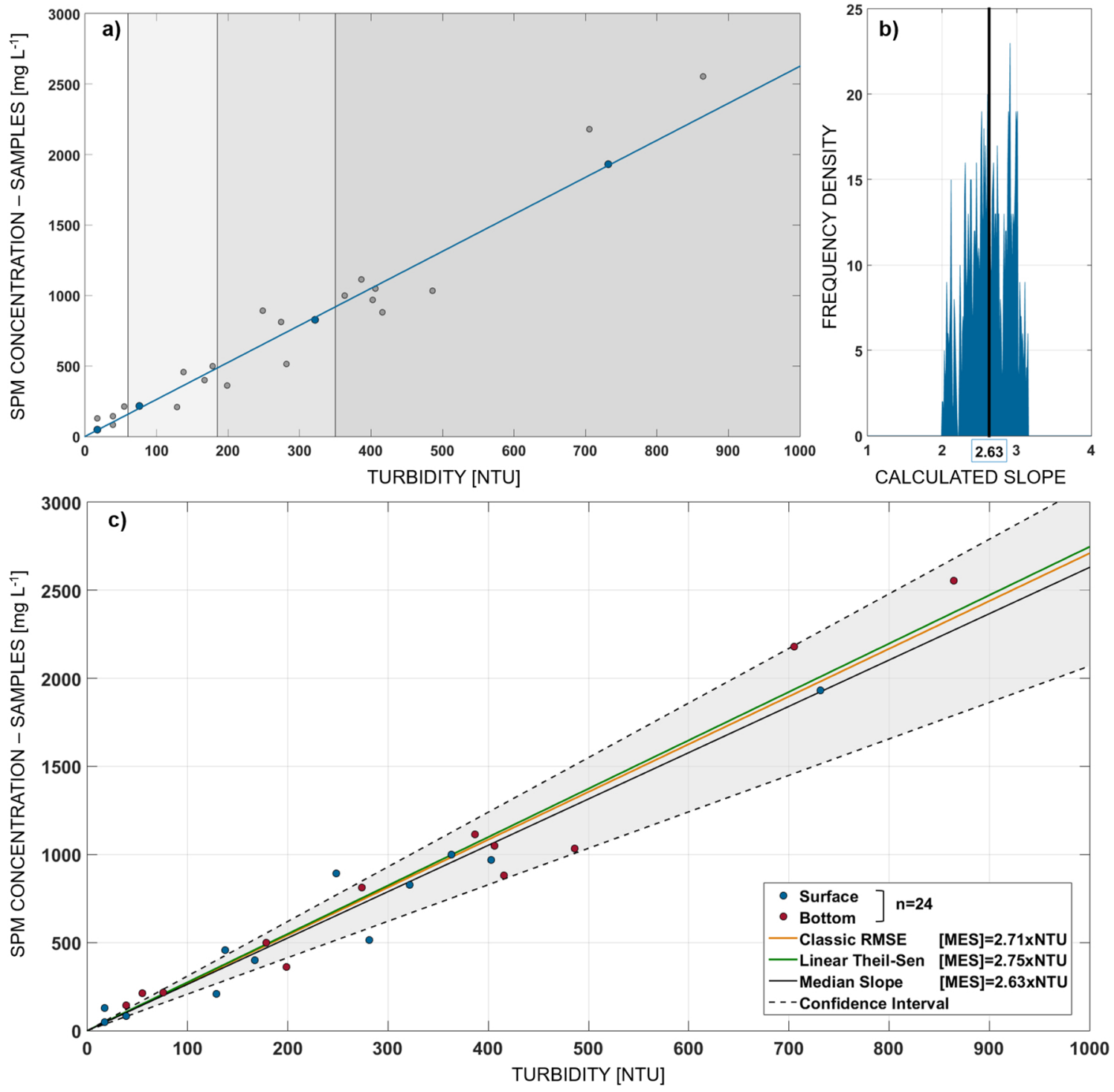

Figure 3

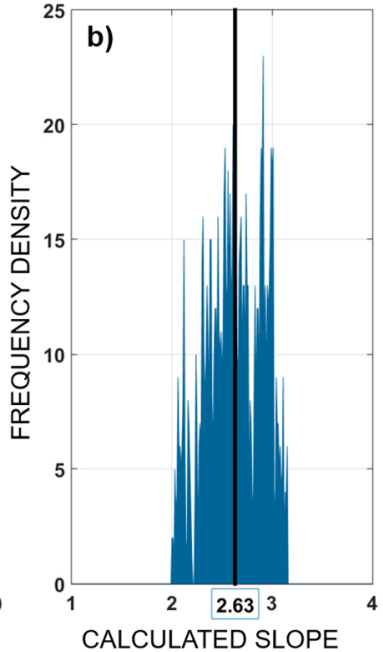

CALCULATED SLOPE 
TMZ
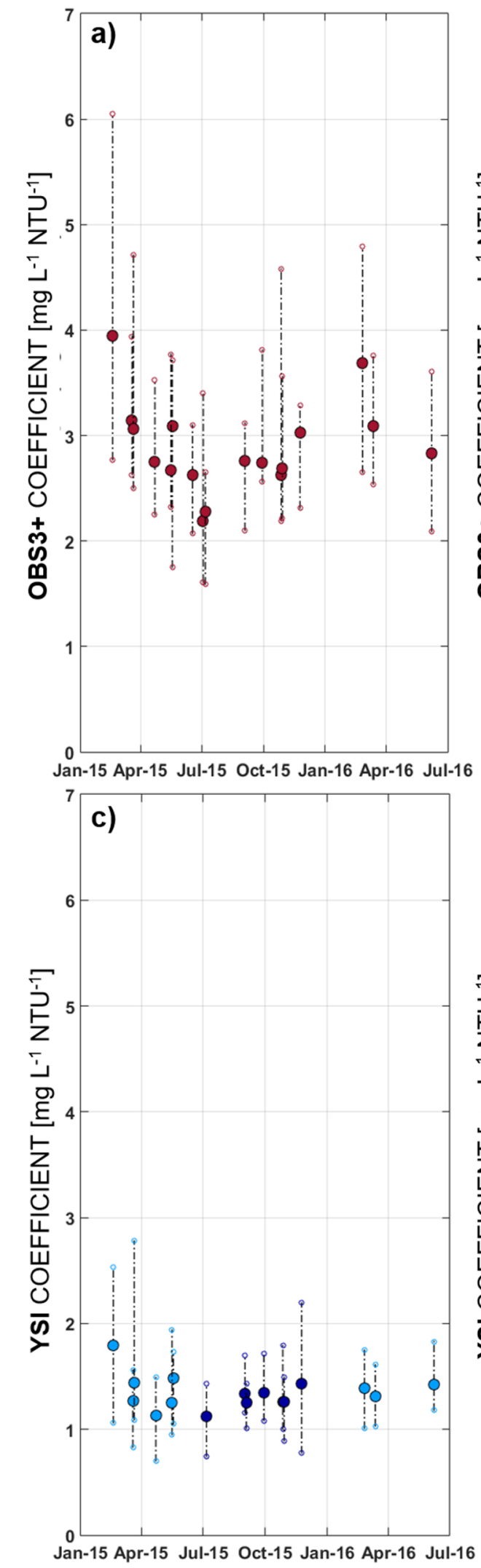

FLUVIAL
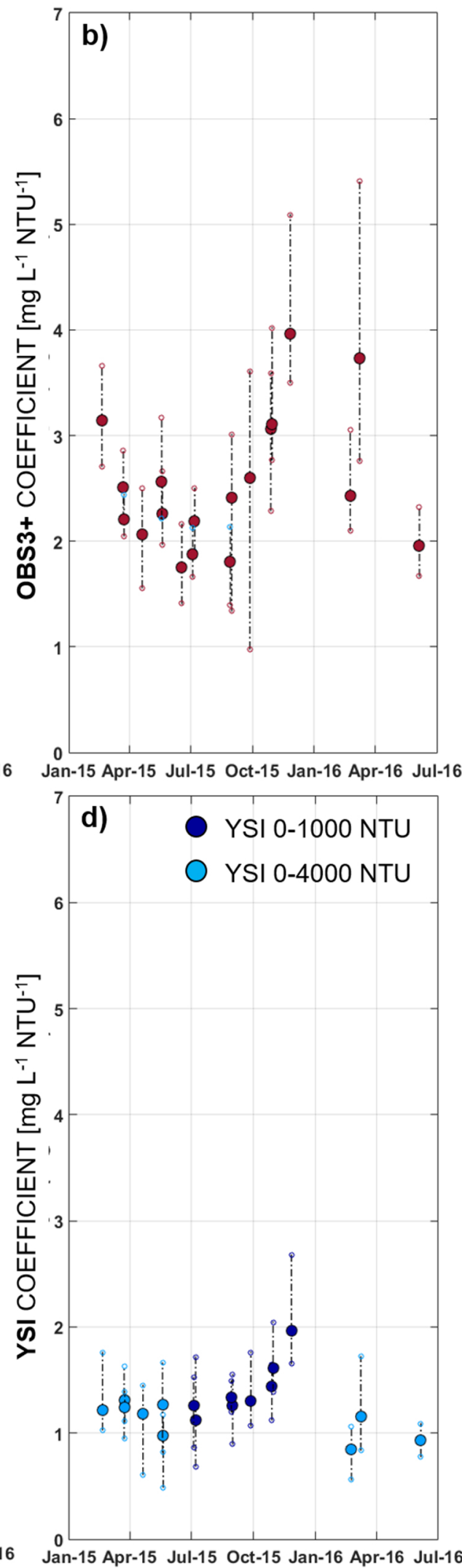

TIME [mm-yy] 


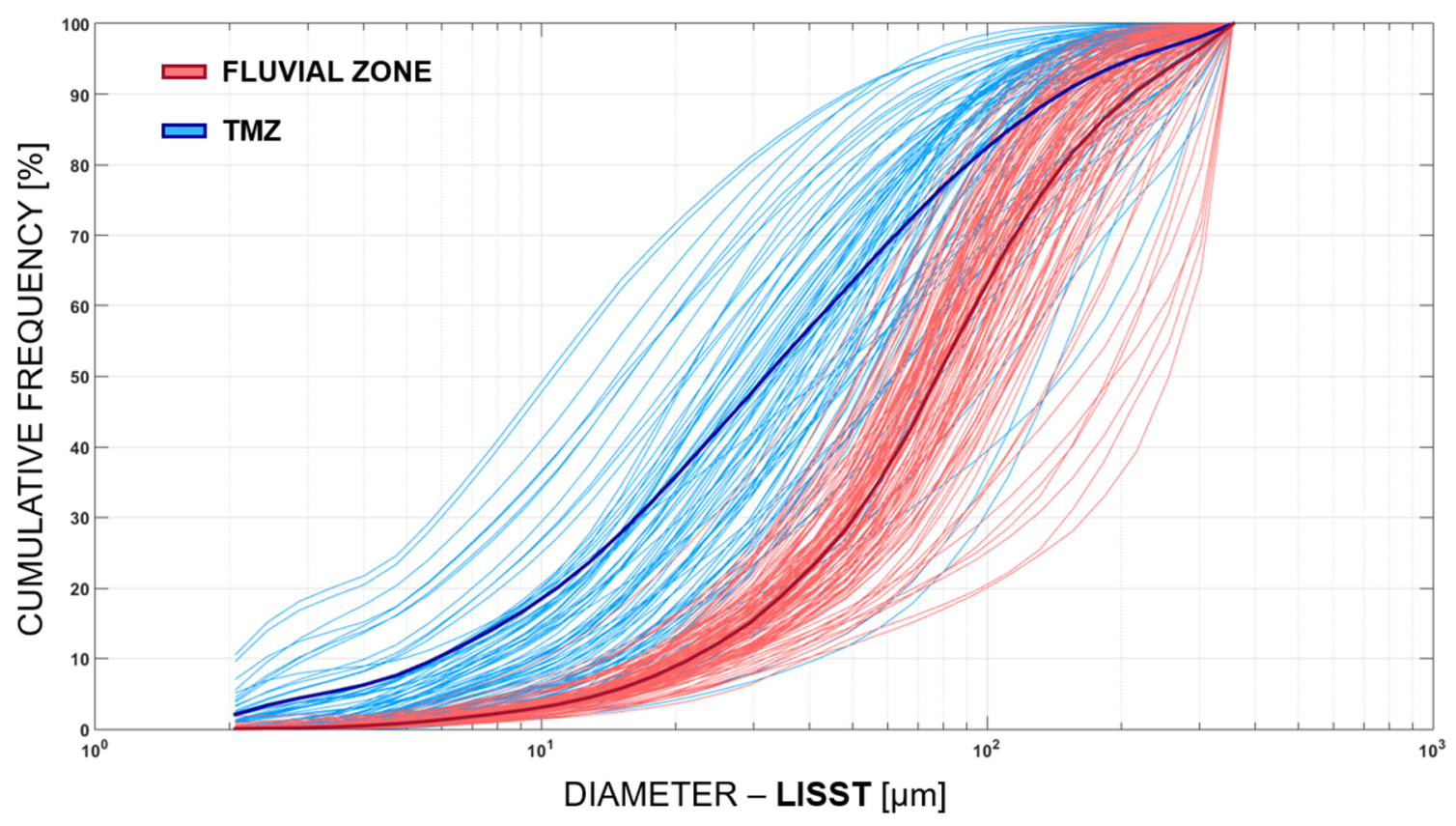

Figure 5 

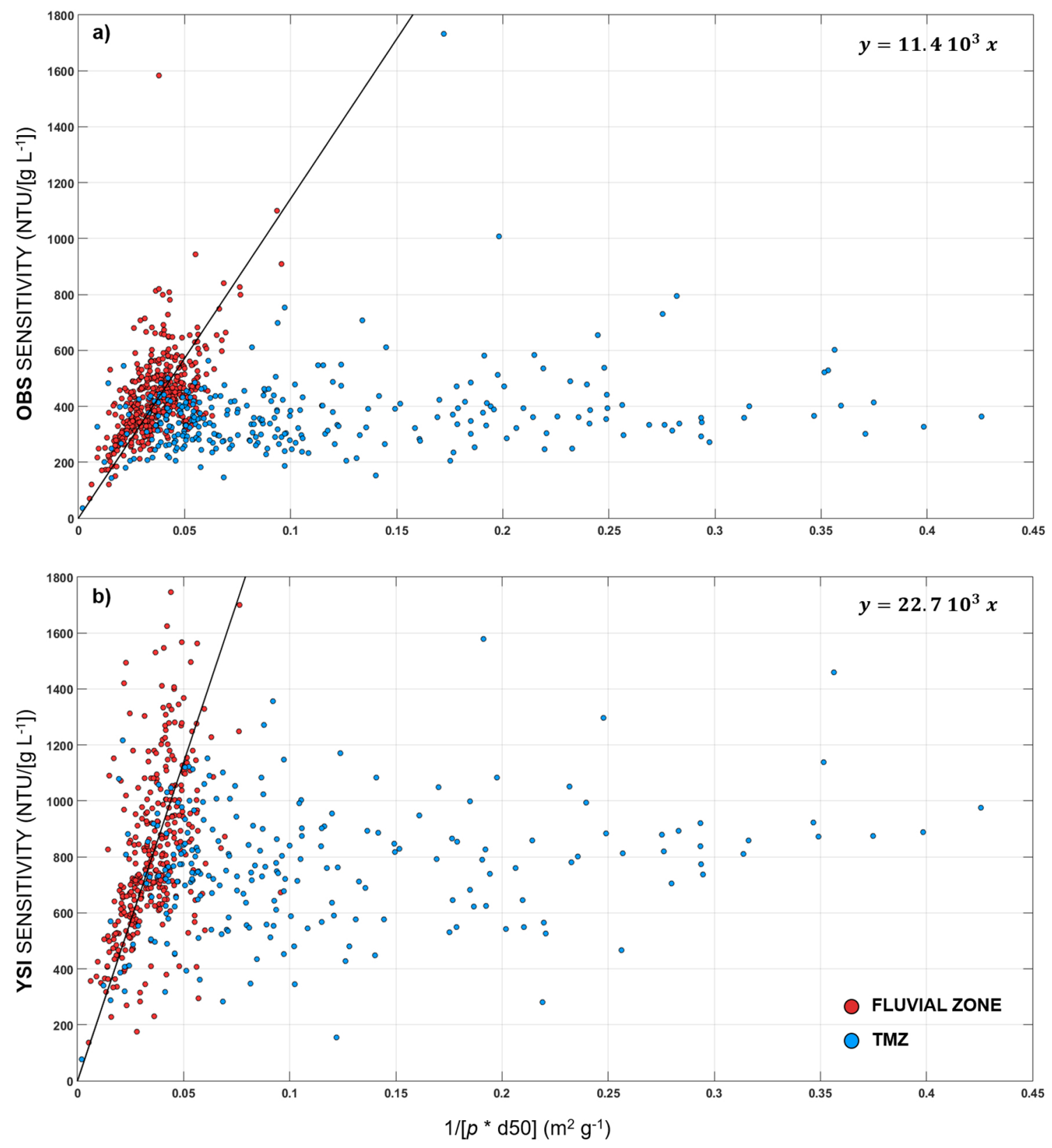

Figure 6 

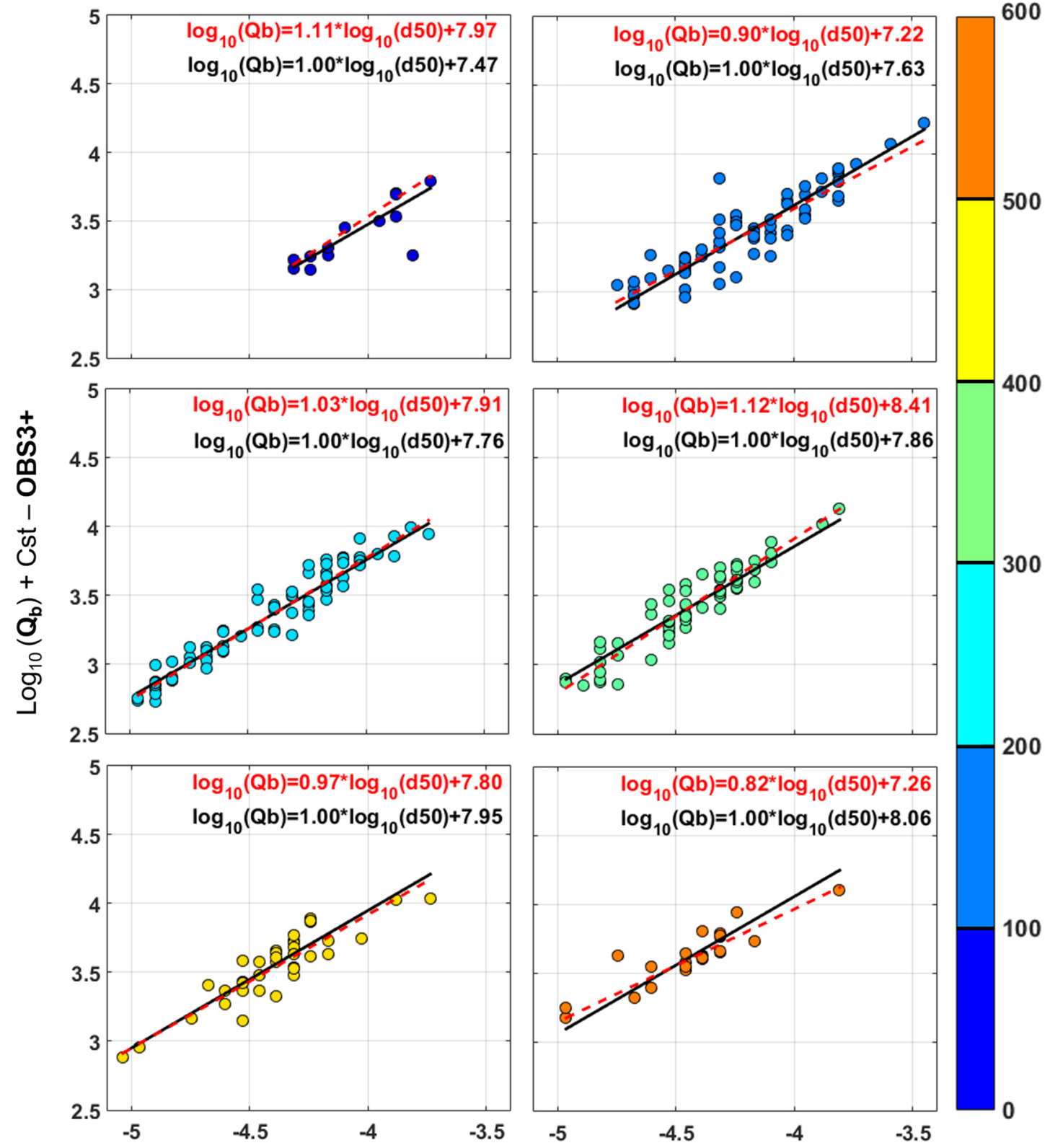

$\log _{10}(\mathrm{~d} 50)[\mathrm{m}]$

Figure 7 


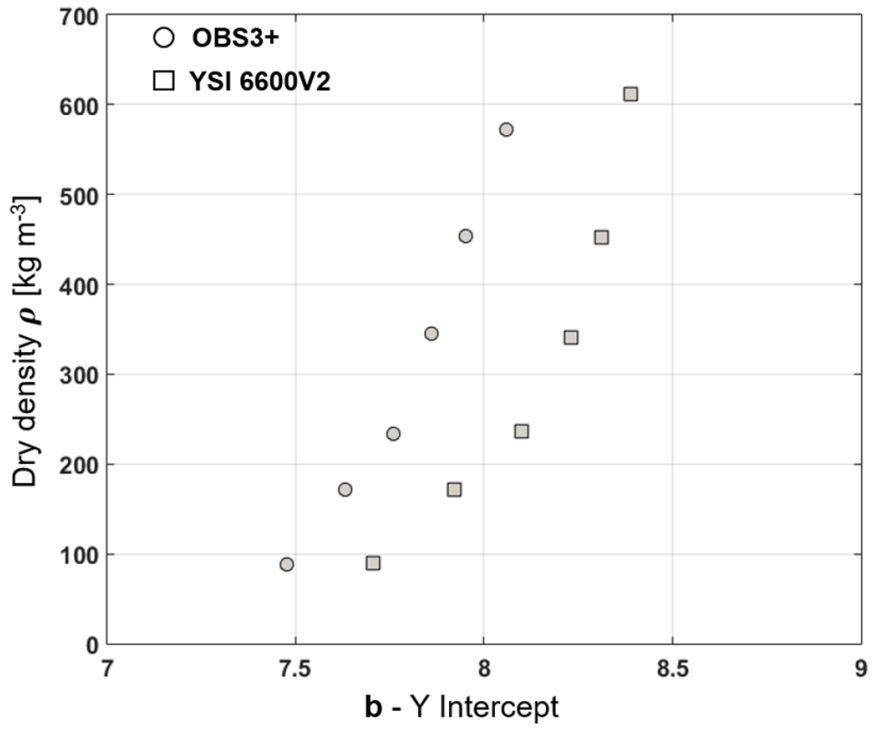

Figure 8 
TMZ

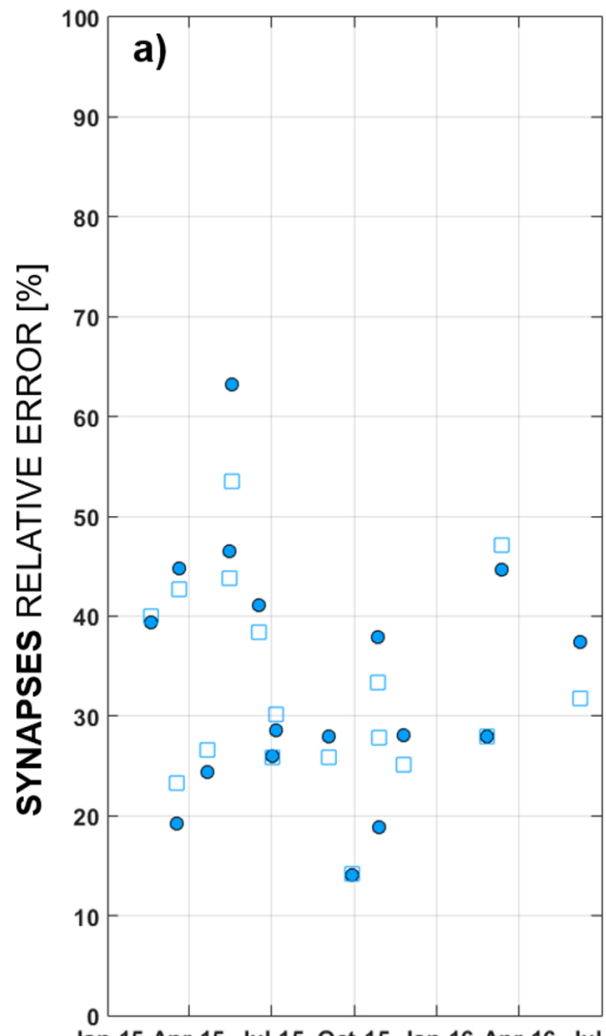

Jan-15 Apr-15 Jul-15 Oct-15 Jan-16 Apr-16 Jul-16
FLUVIAL

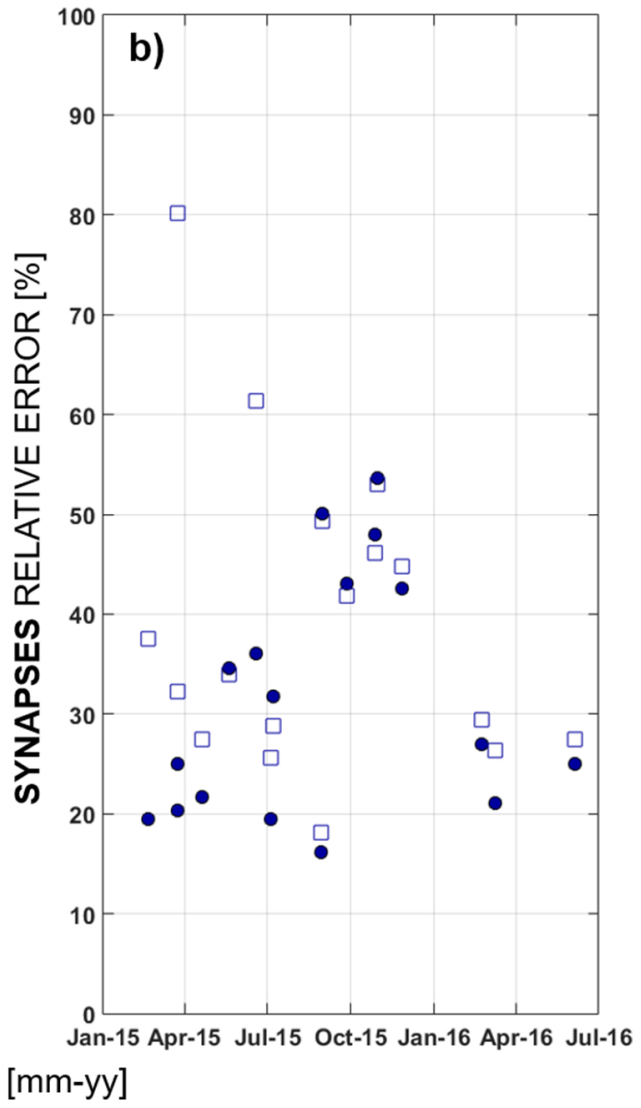

Figure 9 


\section{INTER-SITE CALIBRATION}

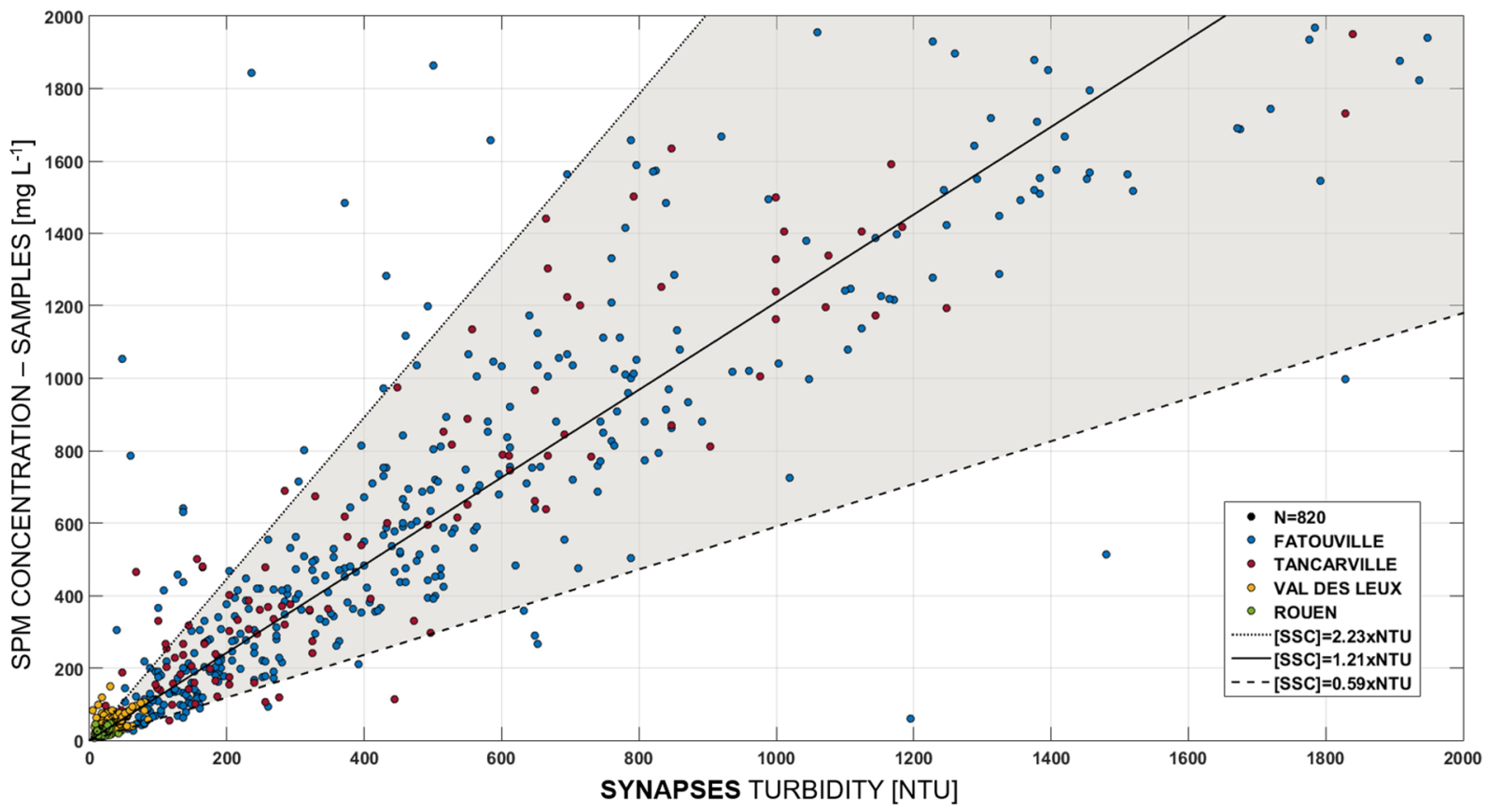

Figure 10 